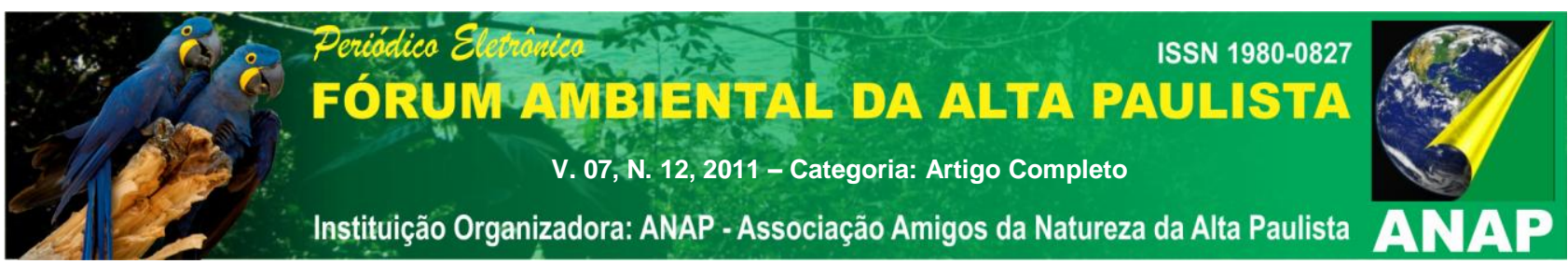

\title{
ANÁLISE DA ÁGUA REALIZADA PELOS ALUNOS DO ENTRO DE EDUCAÇÃO DE JOVES E ADULTOS DE BARRA DO BUGRES
}

\section{Marcelo Franco Leão ${ }^{1}$}

Resumo: Ninguém consegue sobreviver por muito tempo sem água, pois ela, além de ser responsável pela hidratação do corpo, permeia quase todas as funções metabólicas do organismo. O estudo objetivou entender as propriedades físico-químicas da água, bem como o processo de seu tratamento e distribuição. A metodologia adotada foi a da pesquisa de campo realizada na Estação de Tratamento de Água da cidade de Barra do Bugres - MT. O grupo envolvido na pesquisa foi composto por alunos do Centro de Educação de Jovens e Adultos 15 de Outubro, de Barra do Bugres - MT. Foram levantados alguns dados importantes sobre o assunto, tais como: a estrutura molecular da água, os elementos químicos que a compunha, o desenvolvimento do tratamento da água para torná-la potável, os benefícios que são trazidos pelo consumo de uma água com qualidade. Foi pertinente discutir também a questão da má qualidade da água e a sua relação com as diversas patologias desenvolvidas nas pessoas em decorrência do consumo de água sem o devido tratamento.

Palavras chave: Água Potável. Química. Qualidade de Vida.

\section{INTRODUÇÃO}

\footnotetext{
${ }^{1}$ Marcelo Franco Leão - Mestrando em Psicanálise, Educação e Sociedade pelo INSET, especialista em Orientação Educacional pela Faculdade Dom Alberto, pós-graduando em Relações Raciais na Educação e na Sociedade Brasileira pela UFMT, graduado em Química e Física Licenciatura Plena pela UNISC e professor na UNEMAT - Campus de Barra do Bugres - MT, e-mail: marcelofrancoleao@yahoo.com.br
} 
A água é uma substância incolor, insípida e inodora que pode apresentar-se nas formas sólida, líquida ou gasosa. A fórmula molecular da água é $\mathrm{H}_{2} \mathrm{O}$, o que mostra que sua composição se dá por átomos de dois elementos químicos, que são o hidrogênio, cujo símbolo é a letra "H", e o oxigênio com o símbolo "O". Entre esses elementos, ocorrem ligações covalentes e entre moléculas diferentes de água ocorrem as pontes de Hidrogênio. Segundo os estudos de Silva (1999), o ponto de fusão e ebulição são respectivamente $\operatorname{PF}\left(0^{\circ} \mathrm{C}\right)$ e $\operatorname{PE}\left(100^{\circ} \mathrm{C}\right)$ nas condições normais de temperatura e pressão. Vale lembrar que ela cobre mais de dois terço da superfície terrestre e sem ela não existiria vida na terra.

A utilização da água é permanente, especialmente no que se refere ao consumo, pois os animais e os seres humanos necessitam de sua ingestão diária, o que a torna condição para a continuidade da vida. Ninguém consegue sobreviver por muito tempo sem água, pois ela além de alimentar, também é responsável pela hidratação do corpo e isso a torna indispensável.

No entanto para ser consumida com segurança, a água precisa ser potável, sem qualquer mistura que altere e interfira na qualidade de suas propriedades. Encontrá-la pura no ambiente torna-se um problema, pois muitas substâncias se misturam a ela com facilidade pelo fato de ser solvente natural muito eficiente. Na verdade, a sua importância na natureza está ligada a esta característica. "A água forma soluções com uma imensa variedade de substâncias. Ela dissolve sustâncias sólidas, liquidas e gasosa por esse motivo é chamada de solvente universal." (SILVA, 1999, p.54). Por ser de fato um solvente universal, a água consegue dissolver muitas substâncias, as quais muitas vezes alteram a qualidade natural desse líquido, o que a torna até imprópria para o consumo humano.

Segundo Barros (2004), a água própria para o consumo é a potável, este fato está relacionado devido a mesma apresentar qualidades especiais e não conter impurezas como microorganismo, parasitas, ovos ou larvas de animais, nem substância tóxicas como detergentes, mercúrio ou agrotóxicos. A água 
turva, com cheiro ou sabor, indica à presença de misturas que podem representar riscos a saúde de quem a ingerir.

Nem sempre o fato da água apresentar aspecto transparente e límpido garante que a mesma esteja livre de contaminação, até porque os microorganismos são invisíveis ao alcance da nossa visão, o que amplia a necessidade de cuidados com relação à água destinada ao consumo humano. Vale ressaltar que, mesmo a água sendo pura e potável é uma solução, um composto que não afeta a saúde humana, pois ela contém uma pequena quantidade de sais minerais e gases dissolvidos em sua composição.

No entanto, é preciso sublinhar que, infelizmente a água que serve para o consumo humano está cada vez mais sendo afetada pela poluição e contaminação dos rios, córregos e nascentes, tornando-se imprescindível a implantação de sistemas de tratamento para a limpeza da água destinada ao consumo da população. Para Sampaio (1998) é necessário que todos assumam uma postura social diferenciada frente às questões ambientais, sendo alcançada na escola pelo estudo de Ciências com temas vinculados aos impactos ambientais que são de interesse público.

$\mathrm{Na}$ maioria das cidades brasileiras existem sistemas de tratamento e abastecimento de água, ou seja, a água é retirada dos rios, lagos ou fontes, é levada até as estações de tratamento, lá recebe algumas substâncias para eliminar microorganismo, o mau cheiro, o gosto ruim e as impurezas que nela existem, depois passam por grandes filtros e recebe cloro antes de ser distribuída para o consumo das pessoas.

O estado do abastecimento de água e saneamento nos países em desenvolvimento é caótico. Cerca de um milhão e duzentos milhões de pessoas não tem acesso à água potável, e um bilhão e oitocentos milhões não têm acesso a serviços adequados de saneamento. (DIAS, 2001, p. 317)

Referente ao abastecimento de água, isso acontece porque nem sempre o processo de tratamento funciona em conformidade com as normas ou, às vezes, a estrutura e os recursos utilizados nesse processo não dão conta de 
garantir uma efetiva qualidade da água disponibilizada a população. Neste sentido, o estudo objetivou apontar as propriedades físico-químicas desta substância, as etapas do tratamento para torná-la potável, e sua contribuição na continuidade da vida.

\section{MATERIAIS E MÉTODO}

A investigação do problema bem como a intervenção desenvolvida a partir do estudo ocorreram em uma escola publica da rede estadual do município de Barra do Bugres no estado de Mato Grosso, denominada Centro de Educação de Jovens e Adultos "CEJA 15 de Outubro". O estudo foi desenvolvido com os alunos da fase I A do período vespertino e das fases I C, ID, II D e III C do Ensino Médio do período noturno, os quais utilizaram como instrumentos de pesquisa a internet, a coleta de amostras da água, a analise e observação destas amostras e entrevistas com as pessoas ou profissionais responsáveis pelas analises da água na estação de tratamento do município.

Os jovens e adultos dessa escola residem, em sua maioria, no bairro Maracanã que é uma região periférica da cidade, no qual ocorre falta constante de abastecimento de água, portanto aumenta a necessidade de desenvolver uma consciência de preservação e uso racional junto à comunidade escolar e na sociedade como um todo. Outro fato a ser considerado é a escassez deste recurso em alguns lugares do planeta, causada pelo uso indevido, ou ainda, pela contaminação dos mananciais, demonstrando que a utilização dos recursos naturais, sobre tudo a água, é de suma importância para manutenção da vida em nosso planeta.

O presente estudo é classificado como qualitativo uma vez que os resultados foram extraídos pela observação do processo de tratamento, pela análise teórica da bibliografia disponível, pela interpretação de dados reais como a constante falta de água no bairro de localização da escola, pela discussão dos efeitos benéficos da água para os organismos vivos e pela comparação da estrutura química da água e as demais substâncias. Pode 
ainda o estudo ser classificado como bibliográfico pelos meios que serviram para aprofundar o conhecimento a respeito do assunto em estudo. Um dos métodos utilizados foi o da pesquisa - ação, a pesquisa de campo foi realizada.

A pesquisa teórica foi imprescindível para embasar o estudo. $\mathrm{O}$ uso de computadores e da internet do Laboratório de Informática da escola, se fizeram necessários por serem maneiras eficazes para buscar um entendimento maior do conteúdo ministrado.A metodologia utilizada foi investigativa e indagadora, onde os alunos, motivados por uma provocação, buscaram respostas não só através da teoria, mas também, pelo relato de experiências de outras pessoas. Outro método utilizado foi à saída de campo através da visitação da Estação de Tratamento de Água da cidade de Barra do Bugres - MT.

Durante esse processo, também foram proporcionado aos alunos, aulas experimentais com material concreto que possibilitou confrontar as teorias até então pesquisadas com a realidade vivenciada pelos mesmos. 0 estudo levou à compreensão da composição, estrutura e propriedades químicas da água pelos educandos.

A experiência pedagógica foi realizada durante as aulas de Química bem como nas oficinas pedagógicas da área de Ciências Naturais, Matemática e suas tecnologias no decorrer do $1^{0}$ semestre.

\section{RESULTADOS E DISCUSSÕES}

Em virtude da proximidade do "Dia Mundial da Água", foram apresentados pelos professores de Química Marcelo Franco Leão, de Biologia Luzinete Duarte e de Ciências Eli Cordero Weber, vídeos e mensagens que sensibilizaram as turmas reunidas em oficina no salão do CEJA, conhecido como barracão, frente à problemática da água quanto recurso natural, substância fundamental para a vida, seu devido uso, seu custo e o processo de purificação da mesma.

Alguns slides contendo propriedades físico-químicas da água, seu ciclo na natureza, um panorama geral do tratamento e algumas dicas de como economizar e utilizá-la de maneira consciente foram propostos na ocasião. 
Entretanto, não se tratava apenas de uma aula expositiva, mas sim de uma intervenção pedagógica, com informações e com o intuito da participação dos alunos de forma dialogada, para evidenciar o conhecimento prévio que esses já possuíam, sendo que alguns questionamentos foram levantados, o que levou ao desenvolvimento da pesquisa.

Saber sobre sua estrutura molecular, os elementos químicos que a compunha, o desenvolvimento do tratamento da água para torná-la potável e quais os benefícios trazidos pelo consumo de uma água de qualidade, além da composição química de uma água mineral. Essa ação vem ao encontro do pensamento de Silva (1999) ao afirmar que a água é o solvente universal capaz de reagir e formar diversas substâncias e com elas seus benefícios específicos.

No Dia Mundial da Água os alunos foram motivados a trazer garrafinhas de água mineral, e assim, com o material do próprio aluno, trabalhar as informações contidas nos rótulos, sendo dessa maneira incentivados a continuar usando aquelas garrafas no consumo de água durante os períodos de aula, hidratando o corpo e auxiliando nas sinapses cerebrais.

No decorrer das atividades desenvolvidas, teve uma participação dos alunos da Universidade Aberta do Brasil, do curso de Licenciatura Plena em Química pelo IFMT, Mônica Maㅡ Ormelinda de Jesus Costa, Maria Aparecida Flanklin de Freitas Gonçalves, Carlos Alcides de Morais e Leocir Paula, na realização de ensaios experimentais com água do Rio Bugres, o qual abastece a cidade de Barra do Bugres, utilizando sulfato de alumínio para a floculação e cloro ativo para matar microorganismos. Também foram feitas comparações entre a água sem tratamento, dita bruta, e a água coletada nos bebedouros da escola. Os alunos do IFMT trouxeram resultados sobre análises que realizaram na ETA (Estação de Tratamento de Água) da água consumida em Barra do Bugres.

A realização na análise na amostra de água coletada fora positiva, no sentido de que os resultados apresentados estavam todos dentro dos 


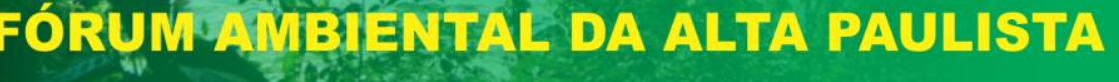 \\ V. 07, N. 12, 2011 - Categoria: Artigo Completo \\ Instituição Organizadora: ANAP - Associação Amigos da Natureza da Alta Paulista}

chats

parâmetros de qualidade da água, o que respondeu positivamente as hipóteses levantadas no trabalho, como se pode perceber no quadro abaixo:

\begin{tabular}{|c|c|c|c|}
\hline $\begin{array}{c}\text { Característico físico- } \\
\text { química }\end{array}$ & $\begin{array}{c}\text { Parâmetros da água } \\
\text { tratada }\end{array}$ & Água bruta & $\begin{array}{c}\text { Água tratada na } \\
\text { escola CEJA "15 de } \\
\text { Outubro" }\end{array}$ \\
\hline $\mathrm{pH}$ & $5,0 \mathrm{a} \mathrm{8,0}$ & 6,59 & 6,0 \\
\hline Cor & $0,0 \mathrm{a} 15$ & 130 & 2,5 \\
\hline Turbidêz & 5,0 & 24,7 & 1,47 \\
\hline Flúor & 0,52 & - & 0,52 \\
\hline Cloro & 0,7 & - & 0,7 \\
\hline Coliformes fecais & Negativo & Positivo & Negativo \\
\hline
\end{tabular}

Fonte: Mônica, Maria Apª , Carlos e Leocir

O resultado obtido na amostragem estava dentro do padrão aceitável da água para o consumo humano, estando, portanto em conformidade com os parâmetros estabelecidos pelo Ministério da Saúde (PORTARIA, no518 de 25.03.2004).

Nesse caso a instrumentalização da química através de pesquisas e experimentos foi um fator muito importante para que o ensino se efetivasse. Ao refletir sobre essa substância vários questionamentos foram levantados, tais como: quais elementos químicos a compõe, quais propriedades são comuns a qualquer porção de água e quais são específicas, quais os benefícios trazidos para o corpo humano por ela, se a água consumida pelos indivíduos desta escola é de qualidade e quais processos são aplicados na água, até a mesma ser consumida. A potabilidade da água levantada por essa comparação vem confirmar o pensamento de Barros (2004) que aponta a água potável como sendo a própria para o consumo humano.

Em virtude da realização do primeiro sábado cultural que ocorreu no dia 15 de maio, foi organizado uma apresentação com os alunos das fases I C e III C do noturno para divulgar alguns resultados alcançados, tais como a contribuição trazida ao conhecer e saber utilizar corretamente a Tabela Periódica dos Elementos Químicos, bem como anunciar as principais características do Hidrogênio e do Oxigênio que constituem a água. A 
apresentação ocorreu com êxito e foi concluída pela caracterização dos elementos químicos e dramatização da música de autoria de Guilherme Arantes que tem como título "Planeta Água".

Também, para o evento cultural foi organizado pelos alunos um stand com o título "A Química da Água" contendo este informações levantadas pela execução do projeto e algumas práticas experimentais como a de floculação. No stand, continha copos de Becker devidamente identificados com a água retirada do Rio Bugres (bruta), com a água aditivada com sulfato de alumínio (contendo resíduos precipitados no fundo) e a água coletada e consumida no CEJA.

Ao iniciar o segundo trimestre, antecedendo o "Dia do Meio Ambiente" que é no dia 05 de Junho, realizou-se uma visita de campo a Estação de Tratamento de Água (ETA) de Barra do Bugres. Na ocasião foram levadas as turmas do vespertino da Área de Ciências da Natureza, Matemática e suas tecnologias, sendo que a turma I A ficou sobre a responsabilidade do professor Marcelo Franco Leão. A coordenação da visita ficou a cargo da professora de Ciências Elzi Godoy. A visita foi bastante proveitosa e os alunos tiveram a oportunidade de visualizar todas as etapas do tratamento, desde a chegada da água bruta do Rio Bugres até o momento de ter sido purificada e assim seguir rumo às residências.

O evento pela passagem do "Dia do Meio Ambiente" reuniu todas as turmas de todos os turnos da escola e serviu para divulgar as etapas do tratamento da água, bem como alertar sobre o uso consciente e as conseqüências que são trazidas pela poluição e desperdício desse precioso recurso natural que ainda dispomos.

A experiência pedagógica intitulada "A Química da Água" foi concluída após o debate realizado pela turma I A do vespertino que analisou os slides com informações sobre as propriedades físico-químicas da água e os resultados obtidos pelas turmas anteriores. Os alunos envolvidos no projeto se tornaram, de certa forma, agentes de conscientização não só dentro da escola, 


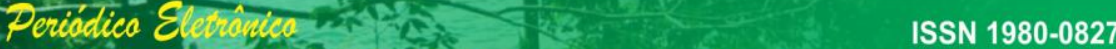 \\ FÓRUM \\ V. 07, N. 12, 2011 - Categoria: Artigo Completo \\ Instituição Organizadora: ANAP - Associação Amigos da Natureza da Alta Paulista}

mas também, nas comunidades onde residem. Assim, a água deve ser considerada por todos, o maior e mais importante recurso da humanidade.

\section{CONCLUSÃO}

Trabalhar de forma a conciliar o ensino da Química em sala de aula com a prática cotidiana vivenciada pelos alunos é uma alternativa aplicável e que traz benefícios para o processo de ensino e aprendizagem, pois faz com que o aluno demonstre mais interesse pela disciplina, bem como pelo tema e sobre tudo o torna consciente da preservação deste precioso recurso, o que deve ser tarefa de todos.

Desenvolver esse projeto não foi só uma forma de realizar pesquisa sobre determinada substância química, mas também um meio pedagógico elucidativo que serviu para aproximar os conteúdos escolares da realidade de vida dos alunos.

Vale lembrar, que a química está presente em tudo que existe, ela é útil seja na análise de substâncias, no tratamento da água, no consumo e na preservação dos recursos naturais, o que vem de encontro às palavras de Silva (1999), ao dizer que a química é a ciência que estuda as transformações que envolvem a matéria, entre elas a água, e a energia, estuda também os fenômenos ocorridos com as substâncias e as transformações trazidas por essas para a natureza.

\section{REFERÊNCIAS}

BARROS, Carlos - Ciências e meio ambiente / Carlos Barros, Wilson Roberto Paulino. - ed. reform. São Paulo: Atica, 2006.

BRASIL. Ministério da Saúde. Portaria no 518 de 25 de março de 2004. Dispõe sobre os procedimentos e Responsabilidades Relativos ao Controle e Vigilância da Qualidade da Água para o Consumo Humano e seu Padrão de Potabilidade. Diário Oficial da União, Brasília, 2004. 


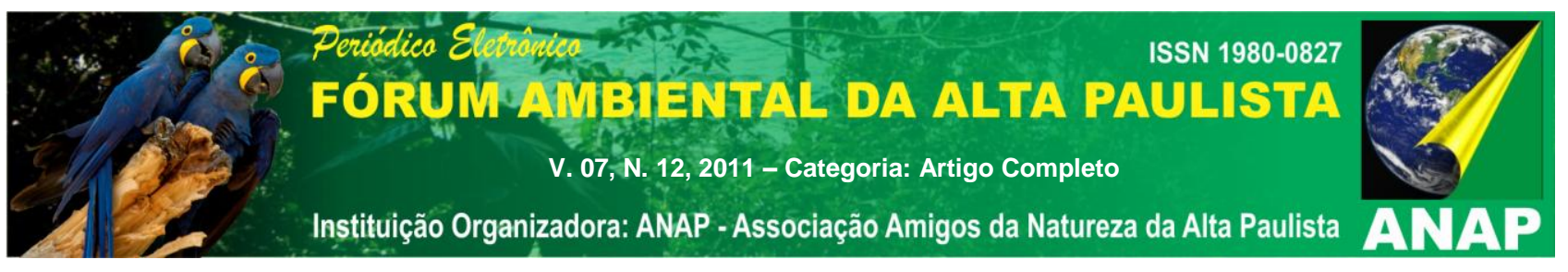

CONTE, M. L; LEOPOLDO, P.R. Avaliação de recursos hídricos: Rio pardo, um exemplo. Rev.Ciência Geográfica-Ensino-Pesquisa-Método. AGB (Associação dos geógrafos Brasileiros), set/dez. 1999, vol III, nำ14, p.25.

DIAS, Genebaldo Freire. Educação Ambiental: princípios e praticas $-7^{\mathfrak{a}}$ ed. - São Paulo: Gaia, 2001

SAMPAIO, Francisco Azevedo de Arruda. Caminhos da Ciência: uma abordagem socioconstrutivista / Francisco Azevedo de Arruda, Sampaio, Aloma Fernandes de Carvalho. - São Paulo:IBEP, 1998.

SILVA, Junior, Cesar da, 1934- Ciências: entendendo a natureza: matéria e

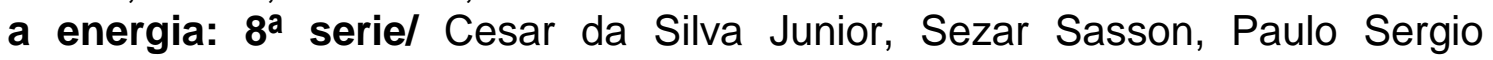
Badaque Sanches.- 16 ed.- São Paulo: Saraiva, 1999. 